\title{
Casa, torre, árbol, muro: hacia una morfología del escenario urbano en las ediciones antiguas de Celestina
}

\author{
Raúl Álvarez-Moreno \\ University of British Columbia
}

Pocas obras de su tiempo se inscriben en la cultura citadina de comienzos de la modernidad como Celestina. Todo lo que en ella ocurre se despliega en el ámbito de la ciudad, recibiendo el espacio urbano atención preferente, tanto en lo físico como en lo conceptual o ideológico. Urbano es el ambiente, los personajes que lo habitan y sus pretensiones materialistas (Abad 231), contándose hasta veintisiete escenas de calle en las que éstos "are en route or returning from meetings or related tasks» (Scarborough 538). Esta presencia de la ciudad y su fisonomía se traslada a los grabados de la Comedia y la Tragicomedia. Su gran éxito entre los lectores hizo que, en un ambiente de competencia entre ediciones, muchas de éstas (veintitrés de treinta aparecidas entre 1499 y 1540) se publicasen ilustradas, lo que habría influido en la lectura y la mejor venta del libro (Alvar 97). Es precisamente en función del vínculo texto-imagen desde donde Carmona Ruiz (2011) traza tres campos principales de estudio de los grabados antiguos: fuentes de los mismos y uso en otras obras, dilucidación de su significado profundo (iconología) y relevancia artística de las ilustraciones de la comedia burgalesa (80). Su estudio de la traducción alemana de 1520 trataría de corregir opiniones vertidas en el pasado (por ejemplo sobre la identidad del grabador), así com o de llamar la atención, mediante un estudio iconográfico, de la superioridad xilográfica de «uno de los mejores libros ilustrados del Renacimiento» (84). En todo caso, aunque podrían añadirse otras vías a las señaladas, como las implicaciones de los grabados en el debate del género de la obra (Rivera 1998), la relación con otras artes (Gómez Moreno 2003) o los vínculos con la iconografía cristiana (Fernández Rivera 2013), lo cierto es que nos falta un examen morfológico de las ilustraciones que aporte sistematicidad y vaya más allá del valor enumerativo-descriptivo de las imágenes respecto al texto. Nuestro artículo examina los escenarios urbanos en los grabados 
de las primeras ediciones españolas de Celestina y las contrasta con los de la traducción alemana de 1520. Partimos de la premisa de que la arquitectura medieval, como parte del espacio, nunca es neutra (Zumthor 36). Tras marcar los aspectos que pudieron influir en la configuración morfológica de estos fondos urbanos y tras valorar su evolución, acabaremos con un análisis de aspectos de forma, como la unidad de composición, la perspectiva, y la escala y proporción.

Además de la importancia de la ciudad en Celestina, otros motivos nos empujan a centrarnos en los escenarios y elementos arquitectónicos urbanos. Primero, son la base en la que se integran y relacionan muchas escenas a través de la compositio o "puesta en posición" que es el espacio pictórico del grabado. Los componentes citadinos de las ilustraciones tienden también a conformarse bajo una serie de esquemas más constantes, de origen alemán en el caso de las ediciones españolas. El paisaje urbano, asimismo, contribuye con un mayor número de material y variables composicionales (luz, escala, dimensiones) a la aproximación morfológica que nos ocupa. Por último, sin olvidar que lo formal-estructural está también afectado por pautas histórico-culturales, el tratamiento del espacio urbano muestra el estado evolutivo de los grabados en relación con otras artes figurativas del periodo, sobre todo la pintura. ${ }^{1}$

Conviene clarificar la terminología para determinar mejor lo que tratamos de hacer. Por un lado, estaría la textualización espacial urbana del libro: cómo Fernando de Rojas (y los receptores) construyen el paisaje citadino con palabras, bien desde la realidad, las fuentes literarias (Lida de Malkiel) o las visuales (Gómez Moreno). Por otro, tendríamos la figuración espacial urbana: cómo dibujantes y grabadores recreaban este espacio, que es en lo que nos interesa ahora. El problema ya lo divisaron Keller y Kinkade en su Iconography in Medieval Spanish Literature. El término iconografía tiene un significado general (arte representativo o figurado, lo pictórico, lo ilustrativo) y otros más concretos; entre estos últimos, su uso se habría expandido desde la identificación y clasificación de imágenes a la explicación de su significado intrínseco y sus relaciones más amplias, o sea, a la iconología (Keller y Kinkade 1). Si bien se omite decirlo, detrás de esta concepción está el esquema triple de Panofsky, quien señalaba tres momentos del acto interpretativo de las obras de arte. Primero el preiconográfico o lectura del sentido fenoménico de las formas y motivos de la imagen, que incluye las configuraciones o patrones de línea y color, escala, volúmenes, inserción de figuras, casas, procedimientos técnicos y de estilo. Segundo el iconográfico o interpretación identificativa, descriptiva

1.- Como la fotografía en el xx, el dibujo se convierte en «arte» precisamente en el xv. Asimismo, conviene recordar el vínculo que entonces unía al pintor y al dibujante con el arquitecto e incluso con el escultor. Todos participaban en recurrir al ingenium por originarse estas artes en la compositio, siendo secundarias las diferencias en el objeto, los materiales y el tema producido por el artífice (Benelli 5). 
y clasificatoria de esas imágenes. Y tercero, el iconológico o penetración en el contenido esencial de las mismas como expresión de valores y contenidos teológicos, filosóficos o políticos (1962: 5-15).

Asumimos metodológicamente la separación del triple proceso, aunque no estamos de acuerdo con un sentido esencialista del arte que vincula el significado sólo al contenido. Estamos de acuerdo, sin embargo, con la atención que Panofsky también reclama para el elemento morfológico de las imágenes y lo aplicamos a los grabados de Celestina. Igualmente creemos que esto no debe realizarse sólo como consignación abstracta de una geometría pura y natural, por ejemplo matematizando unidades modulares y proporcionales con programas informáticos. Debe hacerse de forma sintética (incluyendo lo analítico) y analizando sus estructuras de composición y procedimientos técnicos dentro de pautas históricas. Entre éstas estaría la integración de los grabados en una cultura mercantil del libro que usaba tales recursos para diferenciar el producto de manera ventajosa y reducir gastos. ${ }^{2}$ No era extraño, por ejemplo, tanto entre editores alemanes como entre los radicados en España, que xilograbados y tacos facticios pasasen, por préstamo o venta, de obras de un impresor a las de otros de distintas ciudades y países.

Por lo que respecta al corpus, estudiaremos la primera edición de la Comedia de Burgos (1499) de Fadrique de Basilea, la Tragicomedia sevillana de Jacobo Cromberger (1502/c.1518) y la valenciana de Juan Jofré (1514). Compararemos éstas a la traducción de Cristóbal Wirsung (1520), editada en Augsburgo por su padre Marx y Segismundo Grymm. Nuestra elección se basa en que son las primeras ilustradas e inician el momento de expansión de la obra. ${ }^{3}$ Además, están vinculadas por influencias mutuas entre sus imágenes, de ahí que se hable de "programa visual» compartido entre las tempranas ediciones de Celestina (Alvar 97). Los dibujos de la edición burgalesa establecieron una serie de características que las otras siguieron: consonancia con el texto, grabados de ancho de página, etc. (Snow 256-61), a lo que no debió ser ajeno el tratamiento de la ima-

2.- Factores como el precio del papel, costoso en España por la escasa demanda y ser importado (Griffin 60), no deben descartarse a la hora de considerar el formato y tamaño de libros y grabados.

3.- Las ediciones toledana de 1500 y sevillana de 1501 sólo ilustran el título, sin un fondo relevante para nosotros. A mediados del XVI, casi coincidiendo con la muerte de Rojas (†1541), se abandona la práctica de ilustrar Celestina (Bernt-Kelley 193). La Tragicomedia zaragozana (1507, Jorge Coci) viene sin grabados, aunque pudo tener una portada perdida. Por otra parte, todas las ilustraciones de las ediciones que analizamos, con excepción de la sevillana, pueden consultarse con facilidad en la recientemente inaugurada base de datos en línea Celestina Visual (http://celestinavisual.org). Los grabados sevillanos de Cromberger pueden verse también en la digitalización realizada por la Biblioteca Digital Hispánica a partir del ejemplar conservado en la Biblioteca Nacional de Madrid (R/26575). Están también reproducidos en el artículo de Joseph T. Snow (266-77) citado en la bibliografía. 
gen urbana. ${ }^{4}$ Asimismo, las ediciones valencianas (1514-1529) se inspiraron en los modelos sevillanos de Cromberger, entre los que se supone la existencia de una edición perdida anterior a 1511 (¿1508?) que sigue el modelo de la de Burgos. ${ }^{5}$ Por otro lado, las cuatro ediciones tienen en común haber sido realizadas por impresores alemanes, o copiadas de sus modelos. Finalmente y a diferencia de las tres españolas, observamos por primera vez en la alemana una evolución compositivo-formal que es muy útil para nuestro estudio. ${ }^{6}$

Pasando a los aspectos que pudieron influir en la imagen de las ciudades en nuestras ilustraciones, resulta casi seguro que los dibujantes y grabadores usaron modelos procedentes de editores alemanes que trabajaban Alemania, Suiza o Francia. Aunque falta un estudio unitario profundo, el preponderante papel jugado por alemanes en la primera imprenta española es bien conocido, con una transferencia de habilidades, materiales e influencia en las ilustraciones (Snow (1987), Clive Griffin (2001) o David Rodríguez-Solás (2009). ${ }^{7}$ Esta influencia alemana, junto a la tendencia a acercar texto e ilustración, es inevitable que pasara a vestidos -el tocado flotante de Melibea en Burgos no se usaba en España-, los interiores o el espacio arquitectónico. En concreto, el paisaje urbano de la edición de la Comedia de 1499 podría haberse basado parcialmente

4.- Según Norton, la influencia en Cromberger pudo ser directamente alemana, pero en todo caso similar a la de Fadrique. En lo referente a las imágenes sevillanas de tacos facticios escribe:

These factotum figures... derive from very similar, though larger, figures used in editions of Terence printed at Strasburg in the last decade of the fifteenth century. As far as Spain is concerned, they appear to have originated in Seville, the earliest occurrences that I have noted being found on the title pages of Polono's edition of 3 April 1502 of Santillana's Bias contra Fortuna... and in Polono and Cromberger' Spanish Marco Polo of 28 May 1503. (152)

5.- Ver Snow (256). Según este crítico, el artista comisionado por Jofré imitó de forma intencionada el esquema iconográfico de las ediciones ilustradas salidas de Sevilla, reproduciendo las imágenes visuales asociadas con las anteriores ediciones crombergerianas (263).

6.- Quiero dejar claro de entrada que no trato aquí de fijar o hablar de excelencia artística, de gustos o de fidelidad al texto sino de que su grabador, sea Hans Weiditz o no, crea ya en un mundo xilográfico alemán post-Durero en el que lo estrictamente morfológico cobra más atención frente al contenido respecto al espacio. En esta línea, la asunción de que el autor de las treinta xilografías de Ain hipsche Tragedia de 1520 es Weiditz, o al menos alguien de la escuela de Augsburgo formado con Hans Burgkamair, nos ofrece un contexto de los grabados. Por ejemplo, el hecho de que el Emperador Maximiliano usara este arte para propagar sus hazañas contribuyó a su patrocinio y desarrollo a comienzos del xvi, siendo Augsburgo, como parte del Consejo Imperial, un gran centro xilográfico. Junto a Weiditz, que trabajó allí entre 1512 y 1522, florecieron Leonard Beck y Hans Schaufelein, éste último —-también pintorformado ya directamente en el taller de Durero en Núremberg (ver Huidobro et al. 12-13).

7.- Por ejemplo, sabemos que en 1493 Meinhard Ungut recibió en Sevilla un pedido europeo de más de 50.000 reproducciones de verónicas — vera eikon - (imagen de Cristo impresa en tela), lo que muestra su inclusión en este mercado. Igualmente, Pablo Hurus importó muchas de las entalladuras usadas en sus ediciones zaragozanas, como las del Defensorium inviolatae virginitatis Mariae (1488-90), del sur de Alemania (Needham 71). 
en la edición de las Comedias de Terencio publicadas por Johan Grüninger en Estrasburgo en $1496 .^{8}$ No estamos convencidos, en términos arquitectónicos, de la influencia directa propuesta por Rodríguez Solás del Terencio del impresor alemán Johannes Treschel publicado en Lyon en 1493. Sus fondos y los ambientes de las ilustraciones sólo recrean escenarios teatrales compactos, con más cuidado al detalle en el vestuario y decorado que de la perspectiva. ${ }^{9}$ No son descartables otras posibilidades, como el ambiente urbano de la traducción alemana del Eunuchus publicado en Ulm en 1486, como defiende John T. Cull, ${ }^{10}$ o patrones urbanos procedentes de obras no dramáticas, como las Obras de Horacio de 1498, también de Grüninger. ${ }^{11} \mathrm{Al}$ no existir un modelo único claro para los grabados burgaleses, es creíble postular que el grabador usase su memoria de las ciudades alemanas (reales o pintadas). El uso como modelo de la realidad española de la época, a pesar que habría acercado el producto al mercado español, no parece estar presente. Como en el caso de la textualización espacial urbana, se optó por un modelo genérico centroeuropeo, sin que hayan podido aún detectarse rasgos inequívocos de arquitecturas locales. ${ }^{12}$

8.- Se aprecia en las formas arquitectónicas, la posición y presencia de los árboles en la composición, y en el suelo a base de montículos. Fadrique además lo había hecho antes, presumiblemente con su Esopo de 1496, y definitivamente con el Exemplario contra engaños de 1498, cuyas 116 imágenes tratan de reproducir las de la edición del Directorium humanae vitae (1489), publicada — como la de Grüninger - también en Estrasburgo por Johan Prüss.

9.- Sí vemos, por otro lado, una posible influencia en el dinamismo dramático y la pose de las figuras de esta edición de Terencio. Otra pista seguida — por la influencia de sus interiores en Fadrique (ver Fernández Rivera 2012), bien fuera a través de la Cárcel de amor de 1493 de Hurus, otras ediciones de ésta (1496) o la del propio Olivier de Castilla (1499- es la edición de este último texto editada por Louis Cruse en Ginebra en 1492: L historie d'Olivier de Castille et Artus d'Algarbe. Por ejemplo, el suelo semi-ajedrezado lo encontramos en algún interior de la Comedia de Burgos, como el de la ilustración de Calisto en la cama. No obstante, los espacios externos no son urbanos, con sólo cuatro o cinco grabados con casas que son iglesias en despoblado o palacios con torre, y cuyo estado formal evolutivo es similar a Burgos. Esto se aprecia además en cómo se inscriben en el plano los personajes yacentes.

10.- «Illustrated with fourteen remarkable woodcuts, over five inches by seven in size, and each occupying about three-fourths of a page. The scene is mostly laid in a street, and there is some attempt at perspective in the vista of houses. The figures of the characters are fairly good, but not above the average Ulm work of the time» (Pollard 50).

11.- La disposición trabada de los bloques de edificios y las sombras de sus grabados recuerdan a la edición burgalesa. Por otro lado, las panorámicas de Mitilene, Tebas o Rodas nos dan una idea de lo que pudiera haber sido, de haberse realizado, el grabado con una panorámica de la ciudad celestinesca. Esta última posibilidad debilitaría la procedencia de los grabados celestinescos como argumento para justificar la adscripción de la obra al género dramático tal y como se concebía en la época (ver Griffin 68, Rivera 1998:15 y Rodríguez-Solás 16).

12.- Por ejemplo, sólo en Jofré el segundo piso de ventanas con ajimez sugiere la típica galería corrida de balcones del estilo gótico hispano-flamenco. No se percibe ningún atributo arquitectónico o decorativo mudéjar u oriental. El hecho de que la alemana de 1520 sí tienda a hacerlo, hace pensar que los artistas en España se inspiraron más en patrones ilustrados que 
Dada por sentada esta influencia alemana, intentaremos ir más allá. Seguiremos dos rutas: tratar de esclarecer qué pudo condicionar la elaboración concreta de los modelos alemanes; y valorar el estado en que se hallaba la evolución de estos modelos, que podemos adelantar que están en una «transición figurativa gótica». Dentro de la primera ruta de investigación, un factor importante es la escenografía visualizada por el diseñador al leer o escuchar los textos del teatro romano, los cuáles presentaban la acción en una calle frente a una, dos o tres casas, sin que tengamos que descartar del todo el que pudiera haber visto una representación. ${ }^{13} \mathrm{La}$ imagen genérica de ciudad, adaptada a la realidad centroeuropea contemporánea, podría venir de estas lecturas. La misma procedencia podrían tener los recursos como la abbreviatio o la sinécdoque de usar un sólo árbol para indicar un jardín, o un grupo de casas para toda la ciudad. ${ }^{14}$ Incluso el criterio de elección de las escenas que se ilustran -las más dramáticas- habría afectado la morfología del espacio exterior, como en la preferencia de la edición burgalesa por las escenas "umbralísticas», es decir, al pie de una puerta que separa dos espacios. Aunque la división en dos espacios de los grabados era una técnica pictórica común ${ }^{15}$, esto no quita que la abundancia de escenas con puerta en el teatro romano no contribuyera a su adopción para representar el dinamismo escénico, con entradas y salidas, personajes escuchando, diálogos y apartes. Igualmente podría haber pasado de la visualización textual al grabado el uso de paredes transparentes para que los lectores vean el interior y el exterior a la vez (Fernández Rivera 2012: 121). Esta técnica, como la de la casa de muñecas o puertas elevadas también en Burgos, no es sólo de los grabados teatrales, e incluso pasa de casa-calle a muralla-ciudad en ilustraciones de textos como la Relatio de Simone puero Tridentino (1475), editada en Augsburgo por Günther Zainer.

Dentro del vínculo compositivo señalado entre las artes figurativas, otra influencia en los dibujantes y grabadores podría haber sido la escultura y pintura de la época, que a menudo servían de modelos para la crea-

en la realidad, como menciona Griffin: «Similarly, the illustrators of foreign editions do not hesitate to reproduce their local architecture in their woodcuts» (74).

13.- En este sentido, recordamos la mayor capacidad de memorización auditiva y visual del periodo por la lectura en voz alta y el uso de la imaginería didáctica. Menos probable es el influjo de los escuetos tablados estudiantiles o festivo-patronales, donde se representaban Terencio y Plauto. Por otro lado, Rodríguez-Solás deja constancia de la práctica de los grabadores de servirse de los recursos del mismo texto, como la reduplicación al presentar los apartes y monólogos u otras peculiaridades escénicas $(8-9,15)$.

14.- Deben considerarse a la vez las consecuencias formales del uso de tacos facticios por Grüninger, ajustados a lo teatral como dramatis personae ilustradas y cuyo esquematismo gráfico se habría extendido al espacio urbano.

15.- Como ejemplo valga la ilustración de la fábula de la cabra y el lobo del incunable alemán de las fábulas de Ulrich Boner (1469). En ella el narrador —aunque en la misma viñeta— aparece separado de la escena (Needham 56). 
ción de entalladuras en el xv, como señaló David Areford. ${ }^{16}$ Como este crítico muestra, la dificultad para identificar modelos concretos por mediar la invención, interpretación y variación creativa de los artesanos, no quita que esta imitación fuera una práctica generalizada en toda Europa. El influjo de la pintura podría haber afectado no sólo a la textualización espacial urbana, como ya sugirió Gómez Moreno (2003) para Celestina, sino también a la figuración espacial urbana de los modelos alemanes que siguieron los grabados. Esta influencia afectaría a aspectos como la relación dimensional entre arquitectura y figuras, al efecto amalgamamiento de los edificios en la distancia, o al típico paisaje de fondo en las ventanas (veduta), que no llegó a nuestras ediciones. Finalmente, en esta intertextualidad artístico-figurativa no debe dejarse de lado la pervivencia de la tradición del manuscrito y sus iluminaciones, aún viva en los primeros años de la imprenta. Los manuscritos contenían todavía en esa época imágenes xilográficas pintadas y rubricadas a mano además de prolongar una morfología, de forma que "the transfer of craft from illuminators to painters of woodcuts was a natural continuum» (Fletcher 277). ${ }^{17}$

Menos directo, aunque posible, es el ascendiente del diseño arquitectónico en los grabados. En su libro The geometry of creation (2011), Robert Bork demostró la pervivencia de la gran tradición gótico alemana del dibujo arquitectónico como herramienta de diseño en el xV, que persistió a pesar de las nuevas modas de diseño clásico italianas. A pesar del nivel mayor de complejidad y sofisticación de estos sketches destinados a la construcción, sabemos que eran los mismos grabadores quienes los solían realizar, lo que justifica en parte la pervivencia de las formas arquitectónicas góticas en su lucha con formas clasicistas foráneas. ${ }^{18}$

Debe añadirse, por último, la más que probable deuda del paisaje urbano en los grabados alemanes con varios libros muy populares en la épo-

16.- Sin caer en el tópico del grabado editorial como mero reflejo derivativo de producciones artísticas más logradas, mediante la comparación de fotos y mediante análisis formales, Areford prueba lo común de esta transferencia durante el siglo XV. Usa ejemplos concretos que a veces incluyen expresiones como «contrefacta» o "facta alla similitudine» (121-23). Para lo celestinesco, aunque centrado en lo iconográfico, Fernández Rivera (2013) ha rastreado la influencia del arte visual cristiano en la composición de escena de los grabados de la obra en elementos como la disposición de los personajes en grupos tomando de modelo la Visitación, lo que implica el mencionado trasvase entre artes.

17.- No hemos tenido acceso, desafortunadamente, a los códices medievales con miniaturas de las obras de Terencio para comprobar si ofrecen escenarios urbanos. Aquéllos, según señala Rodríguez-Solás, habrían tenido continuidad en la tradición iconográfica del libro ilustrado (4), lo que los convierte en otra pista a seguir.

18.- Esta línea es de interés asimismo por mostrar una lucha, similar a la de la pintura a finales del XV, entre los modelos góticos y los clásicos como el de De architectura de Vitruvio y el De re aedificatoria de León Battista Alberti. La resistencia al alineamiento y a la geometría arquitectónicos clasicistas, a la geometría lógica y a la racionalidad aritmética (por ejemplo, no tenemos en la verticalidad la geometría «ad quadratum») confirma la pervivencia en Alemania de una cultura arquitectónica gótica a la que no pudo ser ajena el grabado. 
ca. ${ }^{19}$ Entre éstos destacan las vistas de ciudades que aparecen en los muy difundidos libros de viajes como el Viaje de la Tierra Santa de Bernardo de Breidenbach, publicado en 1486 en Mainz y en 1498 en Zaragoza por Hurus. Este libro fue tan señero que, según Alfred Pollard, inauguró un nuevo periodo del libro grabado en Alemania (57). ${ }^{20}$ Lo mismo puede decirse de obras algo posteriores, como el Schatzbehalter oder Schrein der wahren Reichthümer des Heils und ewiger Seligkeit de Stephan Fridolin (1491) y el Liber Chronicarum o Crónica de Núremberg (1493) de Hartmann Schedel, ambos impresos en Núremberg por Antón Koberger. ${ }^{21}$ Es posible que el conocido tópico de la descriptio urbis verbal, clave en libros de viajes y crónicas, tuviera algún efecto en la retórica de la imagen de dibujantes y grabadores. Eso sin contar con las ilustraciones de los mismos, de forma directa o no, a causa de la popularidad de las vistas de ciudades: el primer libro ilustrado publicado en España (Sevilla) en 1480, el Fasciculus temporum del cartujo Werner Rolevinck, es una crónica con varios grabados de este tipo. ${ }^{22}$ Yendo a las ilustraciones celestinescas españolas, si bien la visión espacial citadina carece de una panorámica completa, no están lejos en general en un sentido emulativo pero no reproductivo- del carácter neutro y esquemático de la imaginería y arquitectura del Fasciculus. Ello se ve bien en rasgos de los fragmentos de los tacos de Cromberger, como la linealidad inclinada del alzado, la estampa amalgamada o la tímida apertura de una perspectiva diagonal, compartiendo en términos morfológicos el mismo punto evolutivo. Puede manifestarse por último, que la práctica de usar un mismo grabado para ciudades distintas (por ejemplo Colonia y Atenas)

19.- Un ejemplo serían las ilustraciones de la muy conocida edición del Narrenschiff (1494) de Sebastian Brant, editor de Basilea — como Fadrique - que influyó en Grüninger.

20.- El diseñador de los grabados, Erhard Reuwich, fue un artista e impresor holandés que trabajó en Mainz durante la década de los ochenta del siglo xv y al que Breidenbach llevó consigo en su peregrinación de 1483. La obra, en latín, fue pronto traducida al alemán, al flamenco, al francés y al español.

21.- Sin sugerir influencia directa, al ser su posesión posterior a la escritura de Celestina, la popularidad de estos libros es confirmada por el hecho de que Fernando de Rojas legara en su testamento varios libros de viajes, incluida la traducción citada de la obra de Breidenbach.

22.- La princeps de este libro, publicada en Colonia en 1474 por Arnorld Ther Hoerner, tenía un total de nueve ilustraciones (cuatro de vistas de ciudades) y con ella se inaugura esta influyente práctica (Cornejo 149). Josefina Vidaur y Corteberría, primera estudiosa de la edición sevillana, resalta entre las catorce xilografías las de las ciudades de Nínive, Tréveris, Roma, Bizancio, Atenas y Colonia. Constata también la influencia alemana en las primeras xilografías españolas:

ya que de aquel Imperio eran, en su mayoría, los primeros introductores de la imprenta en España, y no pocas de las ediciones que aquí se hicieron estuvieron inspiradas en otras que habían alcanzado cierto éxito en Alemania [...] En esta primera edición ilustrada [del Fasciculus] se ha seguido en parte, como dice Lyell, la del alemán Valch, hecha en Venecia en 1479, y por ello no está tan acusada nuestra personalidad. (221) 
es algo que, como el Fasciculus, hace también la Crónica de Núremberg años antes que Grüninger usara sus tacos por primera vez.

Respecto al estado evolutivo de estas fuentes alemanas, desde Grüninger a las crónicas, en términos morfológicos estamos todavía ante una fórmula de representación espacial y arquitectónica que no ha asimilado el lenguaje formal ni los procedimientos renacentistas del XV. Asentamos esto sin olvidar factores de distinto tipo, como los materiales (en madera era más difícil ejecutar líneas finas que soportaran el desgaste de la impresión), los económicos (el presupuesto disponible variaba) ${ }^{23}$ o los culturales (muchos todavía pensaban que la imagen distraía al lector y carecían de exigencia representativa). ${ }^{24}$ En resumen, estamos en un mundo artístico-formal alemán pre-Durero en Italia que habría pasado de dichos modelos a las ediciones españolas, notándose ya una evolución en la alemana de 1520 que explica nuestra selección contrastiva. Más decisivo que la conexión teatral podría ser en las ediciones españolas el esfuerzo por reducir costes. Para ello, las xilografías de Burgos y a partir de ellas o directamente Valencia y Sevilla, adoptaron el estilo de bloques facticios creados ya en Alemania o por alemanes. ${ }^{25}$ Esta adopción habría repercutido en la inserción estática de las figuras y en el tratamiento más esquemático del espacio urbano. El resultado es una composición de plano con menor margen para la profundidad, la apuesta por la yuxtaposición al disponer las figuras y un carácter más convencional - acentuado en Sevilla y Valencia - que se habría extendido incluso a las xilografías de contenido narrativo. ${ }^{26}$ Pienso, sin embargo, que las mencionadas influencias no explican todo, con un dato de la evolución formal de la representación que afecta a la mayoría de las potenciales fuentes de los grabados

23.- Por ejemplo, cuando se trata de un único grabado (el de la página del título), se suele poner más cuidado en el diseño y énfasis del detalle. La escasez de medios debió influir también en ediciones de Celestina que surgen en un contexto pictórico más evolucionado, como la veneciana de 1519, con dieciséis xilograbados pero «un esquema pobrísimo de sólo tres bloques que se repiten» (Snow 257).

24.- A pesar de la importancia de la imaginería en lo medieval, siempre se vio con menor estima el detenimiento sensorial en la imagen, por asociarse los sentidos al engaño, e incluso a lo diabólico --de ahí que no tuviese que ser necesariamente representativa. En el siglo Xv ello se vinculó a la resistencia anticlasicista, en la creencia de que la confianza en los sentidos y la apelación a los mismos de los studia humanitatis podía conducir al paganismo.

25.- Por ejemplo, los bloques usados por Estanislao Polono en Sevilla en 1502 en su edición del Bías contra Fortuna del Marqués de Santillana los consiguieron los Cromberger cuando Jacobo Cromberger comenzó a colaborar con Polono, llegando a incorporar Jacobo algunas figuras procedentes del Bías en la Tragicomedia. Para el espacio urbano que nos concierne, se trata de una imaginería alemana de los 90 que se aprecia, por ejemplo, en la primera ilustración en que aparecen Bías y Fortuna (a1r), repetida, tanto en la arquitectura como en el árbol, por varios tacos de nuestra edición.

26.- En los tacos facticios lo fundamental es el personaje y su caracterización (clase, vestido, edad, expresión facial) más que el fondo o el episodio, siendo el lector el que ha que trazar las relaciones y convertirlo en una narrativa en su mente. 
celestinescos. Como apunta Paul Zumthor, los críticos de arte destacaron desde el principio el atraso alemán en la técnica y diseño pictórico. Éste comenta sobre lo morfológico: «El nuevo método se estudia y se practica en los círculos a los que en Florencia, Milán, Venecia, Bolonia, ha llegado el humanismo; en Flandes, donde los Van Eyck lo dominan ya. Alemania, sin embargo, acumulará mucho retraso: hasta el día, hacia 1500, en que Durero se instruya en las prácticas italianas...» (340). ${ }^{27}$ Pollard explica esta postergación - que choca con el mayor desarrollo en los medios mecánicos de la prensa - mediante un apego de los alemanes al gótico y a la tradición iluminativa del manuscrito que pasa al libro impreso y que constata la persistencia en la iluminación de iniciales (8).

Esta peculiaridad evolutiva alemana se aprecia si comparamos los escenarios urbanos más elaborados de las obras impresas de Grüninger, como su Boecio de 1501, con los de los grabados de Durero posteriores a 15051507, fecha de su segundo viaje a Italia..$^{28}$ El influjo directo en la Comedia de 1499 de los diseños de Durero en Basilea (1492-1492) (Carmena 83) es muy poco probable. De haberse producido en nuestras fuentes alemanas, hubiera sido solamente una influencia de los grabados de la etapa formativa de Durero, como los que hizo para el Narrenschiff de Brant o el «San Jerónimo en su celda» (1492). Éstos, aunque apuntan un buen trazo y talento para el detalle, presentan todavía una perspectiva rígida y un paisaje urbano similar al de las obras vistas hasta ahora. No parece haber llegado ni directa ni indirectamente a las ediciones españolas de Celestina el lenguaje espacial arquitectónico de ilustraciones de Durero posteriores a 1496, como "El hijo pródigo", "El caballero y el alabardero y «Hombres en el baño", y menos el de las que siguen a 1507..$^{29}$

27.- «And as for Germany, apart from the works of the half-Italian Michael Pacher, not a single correctly constructed picture appears to have been produced in the entire fifteenth century: that is, not until the adoption of the exact and mathematically grounded theory of the Italians, in particular through the agency of Albrecht Dürer» (Panofsky 1997: 62).

28.- De hecho, como recoge Charles Schmidt en forma de anécdota que alude a España: "Such a difference must have been evident to contemporaries: in 1524, Grüninger was commissioned to print an edition of Ptolemy; when Dürer saw his efforts he considered them laughably crude, but the Spaniards to whom the printer showed his work were evidently most impressed» (xi-xii, cit. Griffin 66). A decir verdad, a la Basilea de Fadrique los cambios llegan realmente tras la estancia de Hans Holbein (1517-19), y en Estrasburgo, donde edita Grüninger y al que sigue el primero, el iniciador es Hans Baldung, formado en Núremberg con Durero hasta 1508 (ver Huidobro et al. 44, 60). Michael Wolgenat, maestro que en Núremberg diseñaba y cortaba, principal ilustrador con su hijastro Wilhelm Pleydenwurff de Der Schatzbehalter o el Liber chronicarum, y con quien se forma Durero justo antes (1486-1489), todavía se mueve dentro de una fórmula medieval. En todo caso, es de esa ciudad y en ese momento desde donde llega Jacobo Cromberger a Sevilla en la última década del siglo xv. Los editores alemanes que trabajan en otras ciudades en los 90, como Augsburgo, Lyon, Ulm o Mainz, no son una excepción a lo dicho.

29.- Es la diferencia que, por ejemplo, se empieza ya a vislumbrar en el contexto hispano (quitando la proporción de las figuras) entre lo urbano de las láminas del Isopete historiado de Hurus (Zaragoza, 1489), la página título del Arnalte y Lucenda de Fabrique (Burgos, 1491) o la 
Otra cosa puede decirse de la edición alemana de 1520, tanto en un sentido general (Augsburgo como Núremberg era ciudad del Consejo) como por haber pasado Durero breves estancias allí, y que incluso artistas de Augsburgo, como Hans Schaufelein se formasen con él. Eso sin contar con el maestro Hans Burgkmair, que tras 1507 viajó a Italia y llevó la influencia italiana a Augsburgo que se ve en esta Escuela (Huidobro et al. 24). Esta combinación puso al alcance de los grabadores de Augsburgo de los años hacia 1520, pese a la estética gótica o los problemas persistentes con la unidad del punto de vista, avances morfológicos que afectan a nuestro objeto de estudio. ${ }^{30}$ Un cotejo atento de la morfología representacional espacio-arquitectónica de las tres ediciones españolas y la alemana confirma el estado evolutivo más avanzado de esta última.

Antes de pasar a su examen, expondré los elementos formales urbanos presentes en nuestro corpus, sin olvidar lo dicho de que, en la época, la pintura (incluyendo dibujo y grabado) y arquitectura tenían un proceso compositivo similar. En éste, la organización del espacio ocupaba un lugar notable ya que controlaba la varietas (ornamento) y la copia (abundancia). En nuestros grabados, los componentes usados para crear y componer el espacio urbano exterior - la calle, plaza (Valencia) o jardín- pertenecen a la arquitectura civil. Junto a la iglesia se echa de menos la torre del reloj, elemento principal en las ciudades del periodo, como se deja entrever en el texto de Celestina. Estamos ante un espacio construido y habitado, con figuras humanas sobreimpuestas o yuxtapuestas. Los elementos principales son casas, torres - no desmochadas-, árboles y muros, almenados o no. De éstos se ven las fachadas, puertas -a veces doveladas-, ventanas simples o con ajimez, contrafuertes, tragaluces, cornisas, terrazas o azoteas, tejados, chimeneas, escalones, aldabas y decoraciones. Los edificios siguen en el estilo arquitectónico modelos alemanes, en una combinación de elementos del gótico final civil no muy marcado (sin ventanas de tracería ojival o contrafuertes estilizados como a veces en Grüninger, aunque hay alguna fachada escalonada en Sevilla) y elementos clasicistas

del mencionado Bías contra Fortuna (1502), con la página título de la edición de Celestina de los Cromberger de 1535.

30.- Estos problemas para lograr la unidad de perspectiva son todavía perceptibles en grabados de Durero como "La Última Cena» (1510). Entre los avances formales conseguidos estarían la mejora en el equilibrio composicional; la superación del estilo primitivo (distribución grupal en escena) -visible en las series de Durero La Pasión grande o La vida de la Virgen (1511)—; el concepto de atmósfera envolvente; el cruzado y finura de líneas capaz de reproducir materiales; el progreso tridimensional — «La Virgen del mono» (1498), «Pilato lavándose las manos" (1512)—; la precisión y menor esquematismo de los conjuntos arquitectónicos — "El ángel con la llave del pozo sin fondo» (1498)»—; o el juego de perspectivas que muestra el famoso «San Antonio» (1519), con la cruz clavada como referente de una vista de Núremberg a base de detallados planos y volúmenes simétricos. A ello se añade el trabajo con la luz de Burgkmair, primero en emplear un bloque tonal con gradaciones en 1508 («medio tono») y en usar el claroscuro con varias planchas en "Amantes sorprendidos por la muerte» (1519). 
que se aprecian más en los interiores (columnas con capiteles sosteniendo estructuras de medio arco, frisos). Son ilustraciones sombreadas que apenas distinguen entre escenas diurnas y nocturnas. Los materiales de construcción no se aprecian bien y hay inconsistencias. La casa de Pleberio a la que llama Celestina en Sevilla, las dovelas de puertas y ventanas de Valencia y el paramento de sillería de los muros de ambas parecen de piedra. Algunos exteriores (y sobre todo los interiores) son de ladrillo en Burgos. Sólo se muestra el empedrado medieval en la sevillana, de forma rectangular, y en la alemana, en que es ovalado e irregular. No tenemos una vista panorámica total de la ciudad, representándose sólo secciones en alguna xilografía de Burgos y taco sevillano o valenciano. Estas vistas pueden leerse como casos de abbreviatio emblemáticas por el total de la ciudad, como en el grabado burgalés en que Calisto sale para la Magdalena y deja la casa para internarse en la ciudad (51r). Este procedimiento contribuye a una impresión más miniaturista que monumental. En la portada de Valencia se ve quizás el mejor ejemplo de esta sinécdoque al ofrecer la ciudad por la plaza, lo que sospecho al compararla con la imagen del auto xill que representa la ejecución de los criados. ${ }^{31}$ Son importantes en Burgos y en Augsburgo (menos en ésta última) los espacios intermedios que dan lugar a escenas umbralísticas o de transición entre los interiores y los exteriores. ${ }^{32}$

No está de más preguntarse si, aparte de crear espacio, la arquitectura citadina de nuestras ediciones es simplemente un fondo decorativo o sirve para desarrollar la narrativa y contar la historia. En la textualización espacial urbana está claro que no estamos ante un backdrop (Scarborough 566), si bien en los grabados españoles, con la excepción de alguna ilustración concreta, como la caída de Calisto o el suicidio de Melibea, se trata de fondos pasivos y subordinados a las figuras o su reacción, lo que no impide que cumplan el objetivo de historiar el relato. Frente a éstas, en las ilustraciones de la edición alemana las demandas narrativas parecen influir más en la morfología estructural de los grabados, dando a veces la sensación como en las ilustraciones del argumento o del auto XIV— de que el espacio

31.- Curiosamente, en la edición alemana, la ejecución no parece ocurrir en la plaza del mercado (nótese que el suelo no está empedrado y hay vegetación) sino, como ocurría a menudo, fuera de la ciudad para así enterrar a los criminales directamente en encrucijadas y caminos.

32.- Su textualización la estudió ya Michel Moner (1996: 280-86), que llamó la atención sobre su importancia teatral y la porosidad entre el espacio privado y público, sugiriendo su uso para perturbar jerarquías sociales, morales y textuales. Kristin Brookes (2000) los vio como espacios simbólicos liminares de subversión del orden patriarcal al penetrarse, sentido iconológico en el que ya incidió Ana Isabel Montero (2005): la puerta no sería sólo una estrategia narrativa para enlazar dos acciones del mismo auto sino evocaría el himen de Melibea. Antes, Rivera (1995) había enfatizado la relevancia de esas escenas impresas en Burgos para la concepción integral de texto e imagen, mejorando y encarnando visualmente la puerta la riqueza y apertura del texto. 
urbano se planteó primero para articular argumento y figuras, aunque el dibujante nunca llegue a dominar del todo el plano compositivo.

Respecto a la unidad formal del conjunto representado, aunque el monocromatismo ayuda, la multiplicidad de puntos de vista, dimensiones y proporciones aleja a los grabados de nuestras ediciones españolas de la revolución pictórica formalista que culmina el Renacimiento y por 1434 León B. Alberti llamaba costruzione legittima. Manuel Abad relacionó ya varias portadas celestinescas, por su distribución espacial e icónica, con «las obras de los miniaturistas medievales y también de los primitivos italianos» (230). En las escenas urbanas españolas coexisten varias líneas de fuga que no convergen en un punto de la imagen y que orientan el espacio hacia distintos focos, como en la portada valenciana o en la ilustración burgalesa del suicidio de Melibea (87r). El resultado es un plano en que la homogeneidad o coherencia de la materia presentada descansa en una composición de grupo, al servicio de la narrativa textual o mental pero sin una lógica compositiva visual basada en una forma independiente y simétrica que se proyecte en un espacio unificado. A esta composición contribuye la división del plano en dos o más partes o escenas - que puede proceder o no del texto- mediante un muro o una línea vertical en varios grabados burgaleses, así como la representación de las escenas con tacos facticios en la valenciana y sevillana. Con todo, por su estilo y las razones morfológicas expuestas, tampoco se logra una unidad compositiva en las ilustraciones no divididas, sean de una escena (Burgos 84r) o de dos (35v). En las ilustraciones fraccionadas, diversos sucesos que acontecen de forma lineal o coetánea en el texto en espacios distintos se presentan de forma simultánea y adyacente. Fernández Rivera sugirió que estábamos ante una tradición de la pintura medieval que trataba el espacio de forma más simbólica que realista (2012: 120). En efecto, se trata de la pervivencia de la "perspectiva artificial», herencia del estilo cristalino cristiano: el artista tomaba posesión del espacio figuradamente, ofreciendo una compositio más intelectual que ocular, presentando yuxtaposiciones que el espectador reorganizaba en su cabeza, generalmente basándose en una historia conocida. ${ }^{33}$

De modo diferente, en la edición alemana Weiditz unifica las escenas de doble o triple panel de las españolas. Si bien no logra un espacio urbano totalmente ensamblado en relación a un punto de vista único, grabados como el tercero del auto I muestran su intento de hacer confluir las líneas (muro-puerta-cornisa-figuras) hacia un mismo punto geométrico.

33.- Aunque en nuestro caso estemos más ante una interacción visual-referencial con el texto, que es muy "moderna» por la movilidad icónica y la actitud activa que exige al receptor, detrás de la técnica pictórica en sí, asociada a lo moral y que en lo formal liberaba de componer el espacio, estaba el antiformalismo cristiano. Para éste, lo esencial no era lo que se veía (la forma sensual) sino la correalidad simbólica, espiritual y superior a la que refería lo representado. 
Usa así de la profundidad y la perspectiva para dar la sensación de interioridad. Se muestra así su intención de que el espacio urbano se constituya a sí mismo en el ojo y no tenga que ser procesado en la mente del lectorespectador. El resultado es un conjunto más homogéneo. Sin eliminarse del todo el efecto de ser una proyección artificiosa, sí hay menor rigidez y aislamiento en las sub-escenas individuales, que están más integradas en el espacio por el movimiento o el gesto de los cuerpos, así como por el tratamiento perspectivista (ver el grabado del Auto XI). Por ello, aunque en las ilustraciones alemanas la imagen visual no está del todo estabilizada, se percibe ya la transición hacia una perspectiva central. Por ejemplo, en la escena del jardín del argumento los tres niveles de menor a mayor distancia con respecto al espectador y la disposición circular envolvente del muro están ya unidos para crear en "efecto íntimo» el hortus conclusus.

A diferencia de esto, los grabados españoles no ofrecen una sistematización coordinada y consistente de la perspectiva, lo que da a su morfología urbana una configuración más psicológica que geométrica. ${ }^{34} \mathrm{En}$ los conjuntos arquitectónicos de Burgos y Sevilla, los edificios se apiñan unos contra otros, sin una simetría lineal y volumétrica coherente, con líneas que se fugan fuera del grabado en distintas direcciones. Siguen aún coexistiendo puntos de vista altos y bajos, o izquierdos y derechos. Por ejemplo, si miramos el grupo arquitectónico del grabado burgalés en que Celestina avanza hacia la casa de Melibea con el hilado (20v), se observa no sólo que los juegos de sombra apenas consiguen transmitir distancias y profundidades sino que alternan las líneas y puntos de vista horizontales referidos a los edificios. Así, la casa de la derecha está vista desde el lateral, mientras que la torre anexa lo está desde el frente. ${ }^{35}$ Tampoco el artista ha logrado integrar dentro del espacio urbano la figura de la vieja, que parece sobreimpresionada. ${ }^{36}$

La movilidad icónica resultante de la dispersión del punto de vista se acompaña de una solución desigual de la profundidad. Pese a que hay esfuerzo por representar elementos tridimensionales -incluyendo el escorzo-, se hace según el modelo medieval, sin conseguir intensidad de

34.- No ocurre siquiera ni en la portada de Valencia, que representa una plaza que cuida más la perspectiva y que corresponde al mismo estado evolutivo que el Eunuchus de 1486.

35.- Ello contrasta, por ejemplo, con el grabado alemán del auto xv que describe la despedida de Areúsa y Elicia a Centurio. En este grabado la casa del fondo es percibida desde la misma posición que el resto.

36.- En las ilustraciones españolas ni los personajes ni los objetos se inscriben normalmente en el plano de forma natural, en una fusión ya generalizada en la pintura coetánea o grabados como el aludido de "La virgen y el mono» (1498). Lo más llamativo es la inscripción en un plano flotante de los personajes en Valencia. Sin embargo, también se aprecia en cómo interactúan las figuras con los edificios que las contienen. Una muestra ilustrativa es el halcón, superpuesto en el árbol en Burgos (1r), frente a la inserción de Weiditz (auto I, grabado primero). De forma tampoco muy sofisticada — poda las hojas alrededor-, Weidtz consigue empero un efecto más natural. 
volumen. En la mayoría de los casos, el resultado es que la relación cuerpo y espacio se reducen a una franja bidimensional en la que la perspectiva se trata de crear poniendo un elemento detrás de otro pero sin control de las distancias. Las magnitudes pueden disminuir con la lejanía, pero esta disminución no es constante y suele ser alterada por figuras fuera de proporción. Un ejemplo indicativo es la visión del interior de las ventanas con personajes en Valencia, donde no existe trasvase panorámico interno frente al ilusionismo espacial que sí logran grabados de la alemana como el primero del auto XII.

Si examinamos la anchura y la altura, los conjuntos arquitectónicos de los laterales de los grabados españoles son asimétricos al no conformarse a un modelo axial congruente. En la anchura es obvio, a causa de la división escénica de los grabados burgaleses antes aludida, pero también afecta a las ilustraciones que no la presentan. En todo caso, en grabados umbralísticos de Burgos, como el del auto Iv en que Alisa y su paje van a visitar a su hermana mientras Celestina se queda con Melibea (24v), el diseño recurre a colocar a Lucrecia en una posición de bisagra, que no aparece en el texto, para dar cierta unidad al grabado. Para la altura, la perspectiva se consigue con un isocefalismo medieval (las cabezas de las figuras guardan la misma altura) que pasa de los tacos a las xilografías. La irregularidad del piso - a veces a modo de montículos- o su inexistencia, como en Valencia, no contribuye a transmitir la idea de equilibrio espacial horizontal. Paradójicamente, esta desigualdad del suelo encaja mejor con la cosmovisión del texto desde un punto de vista iconológico. $^{37}$ En todo caso, ni la altura, ni sobre todo la anchura de los grabados españoles comunican a través de lo urbano esa idea de continuidad, de prolongación espacial del plano que, pese al corte de todo grabado, sí logran algunos alemanes con un perspectivismo diagonal que contrarresta el típico efecto de "enlatado».

La luz es la clave en imágenes y blanco y negro para crear un espacio percibido como tal. Por ello, en todos los grabados que nos ocupan se intenta representarla mediante el sombreado lineal sobre edificios y personajes. Esta representación de la luz varía entre las ediciones. ${ }^{38} \mathrm{Su}$ ejecución para crear distancia es diferente incluso entre las españolas, con más cuidado en Burgos. Así ocurre con los edificios del grabado de Calisto con la cadena en el acto XI (67r), a los que se puede aplicar lo que María

37.- La textualización espacial urbana nos muestra unos espacios irregulares, desiguales, con un suelo donde los personajes pueden resbalar, caerse en un hoyo, en definitiva «sites of potential disaster» (Scarborough 542). Este concepto del espacio ayudaría a trasmitir la sensación de mundo peligroso, móvil, donde todo es frágil y provisional.

38.- Weiditz es el único que, como Durero y Burgkmair, acompaña las líneas diagonales, verticales u horizontales con líneas cruzadas de efecto punteado para conseguir gradación de luz, como en el grabado segundo del auto XII (muerte de Celestina), dando así amplitud al espacio interior. 
Rosa Fraxanet dijo de los diseños de Cárcel de amor, que muestran «de una manera tímida y torpe lo que podría ser la técnica del claro-oscuro realizada con pequeñas líneas diagonales que dan un ligero sombreado a las ilustraciones» (430). De nuevo vemos aquí una diferencia fundamental con la edición de Augsburgo - donde, no se olvide, ejercía su magisterio Burgkmair-, al ser ésta la única que proyecta sobre el suelo las sombras de los personajes. ${ }^{39}$ Una buena muestra de esta técnica es el grabado del auto xx con el suicidio de Melibea. Amén del detalle de la sombra del cuerpo sobre la torre al caer, en el grabado se aprecia como la luz entra de forma unificada en diagonal por la derecha. Los laterales de los edificios de ese lado e incluso el suelo cercano a ellos están en sombra. La figura de Pleberio es más grande por razones exclusivamente formales (está más cerca del que mira) y no por razones simbólicas: ser hombre, mayor y padre. Este uso perspectivista de la sombra adquiere su máxima expresión en la xilografía del jardín que ilustra el argumento, una escena nocturna a la luz de la luna. En ella, una buena gradación de sombras incluye incluso la sombra del árbol en el muro, mientras que la parte derecha está iluminada por efecto de un segundo foco de luz procedente de la calle.

De forma muy concisa trataremos ahora de la estructura y movimiento, la proporción y escala o la verticalidad. Estructuralmente, los conjuntos arquitectónicos de los grabados se conciben como bloques volumétricos poco complejos, tendiéndose hacia el esquematismo de los modelos alemanes antes citados. ${ }^{40}$ Más que la tendencia naturalista prima la convención, tanto en los grabados facticios valencianos como en el apiñamiento de perspectiva comprimida de Burgos y Sevilla. Incluso cuando sólo se presentan partes externas del edificio, se tiende a una geometrización muy básica, con un diseño gobernado más por convenciones de procedimiento que por cánones de forma y proporción. Esta geometrización se extiende a los árboles - muy diferentes en su esquematismo de la variedad y densidad que presentan en la edición de Augsburgo- e incluso a la anatomía humana, que está formada a base de rectángulos triangulados y esferas que no permiten una clara individualización de las figuras. Aunque no son hieráticas, las figuras que habitan este espacio urbano poseen por lo general un sentido dinámico limitado. Ello no sólo afecta a los tacos facticios sino también en cierto modo a las ilustraciones de página completa de Burgos. Un ejemplo de esta limitación en el dinamismo son los segundos grabados del auto XII (muerte de la alcahueta y los criados)

39. - La proyección de la sombra del cuerpo, usada en la época clásica y no en la Edad Media, vuelve a generalizarse como atributo de la pintura en perspectiva gracias a los avances flamencos y clásicos en el xv.

40.- Estamos casi siempre ante volúmenes tipo «caja de cartón», en los que todos los lados se aplanan. Los de Weiditz, por el contrario, despliegan más variedad y cuidado en la linealidad geométrica, enfatizada por detalles como las cornisas y zócalos (ver grabado del auto xi) y una circumscriptio más marcada para las construcciones. 
en Valencia y Sevilla. En los dos casos la yuxtaposición en diagonal recta y no sincronizada entre Pármeno cayendo desde la ventana y Sempronio en el suelo afecta a la unidad focal. Ello contrasta con el movimiento de algunas xilografías alemanas, como la que representa la muerte de la alcahueta (auto XII, grabado segundo), en la que el acto de Sempronio en el momento de derribar a Celestina es acompañado por una expresiva y arqueada Elicia; o la de la representación de los criados trasladando el cadáver de Calisto (auto XIX), en la que, gracias a la expresión de las caras y la posición flexionada de rodillas y brazos, se transmite mayor sensación de elasticidad y dinamismo.

Respecto a la escala y proporción, estamos lejos igualmente del espíritu innovador del XV de unas artes plásticas influidas por los textos aristotélicos y de Vitruvio, según el cual la arquitectura debía armonizar sus medidas con el cuerpo humano.$^{41} \mathrm{La}$ escala depende del tratamiento del espacio en gran medida y en los grabados españoles no se guarda una proporción regular entre el tamaño de los objetos representados -ver por ejemplo Burgos (62r). Este efecto es perceptible al comparar la dimensión de puertas, ventanas y personajes con los árboles o los conjuntos arquitectónicos circundantes. Ocurre sobre todo al contrastar los muros del jardín con el resto de la imagen: su perspectiva no comunica la sensación de gran altura que les atribuye el texto y que es la causa de la muerte de Calisto (ver Valencia, auto XIV). Esta falta de proporción de los muros la justifica en parte la necesidad representativa, no fácil de resolver, de mostrar el dentro y el fuera del jardín de Melibea. Por ello, Weiditz recurre a una perspectiva en semipicado, desde lo que se supone el puesto de vigilancia más elevado de los criados (argumento y auto XIV). Éste obtiene mejor resultado en la ilustración vista del cuerpo de Calisto (auto XIX), en la que el muro aparenta más verticalidad. A ello contribuye el ser un primer plano, la proyección sugerida por los árboles cortados por el borde superior de éste, el tamaño de la escala, así como las distintas distancias del fondo que envuelven la escena e integran mejor el jardín en lo urbano.

De lo dicho se aviene un acercamiento al espacio construido que acentúa la dimensión horizontal de la imagen. A ello coadyuva el formato apaisado en cuarto y la disposición de los grabados a lo ancho de la página, sin olvidar la reducción en el número de hojas de las ediciones, que van de 92 en Burgos a 64 en Sevilla y 70 en Valencia frente a las más de 150 hojas de la alemana. Estos condicionantes, así como la menor altura para el grabado (62 milímetros en Burgos frente a 70 en Augsburgo), no quitan para que los intentos de producir verticalidad en las ilustraciones

41.- A veces se aprecian incluso los cuerpos con «dobles cabezas» (cabezas de tamaño doble del que deberían tener para encajar con el cuerpo, como en Valencia, por ejemplo), o la perspectiva jerárquica, que representa lo más importante como más grande en el mismo eje (la figura de Calisto en Burgos). Esta práctica es una supervivencia de un mundo representativo medieval basado más en el conocimiento que en la visión. 
españolas sean más bien tímidos y revelen un estadio evolutivo anterior. En las ediciones españolas se trata de crear la visión ascensional recurriendo al tamaño de las puertas o la estilización de las ventanas en Burgos e incluso al recurso insuficiente de elevar los cipreses y otros árboles sobre el muro en Sevilla y Valencia. La técnica de las puertas elevadas, usada en Burgos por ejemplo en la escena del suicidio de Melibea (87r), alarga la puerta de la casa a la derecha para transmitir la idea de alzado a la vez que para mantener la proporción de las figuras en plano. ${ }^{42} \mathrm{La}$ torre, de gran relevancia en la iconografía e iconología urbana de la obra, se intenta alzar poniendo gente en la azotea (Valencia), con sólo Burgos logrando algún efecto de elevación al cortar el plano y ofrecerla en perspectiva con las casas. Es la misma técnica usada por Weiditz, quien consigue más verticalidad en los grabados del auto XX y segundo del XXI al representar sólo la base de la torre pero añadiendo profundidad a los edificios anexos mediante un juego de perspectivas. ${ }^{43}$

En conclusión, el análisis morfológico o pre-iconográfico de los fondos urbanos de las ilustraciones primeras de Celestina muestra una influencia de patrones alemanes que por copia, recreación o superposición memorística no tuvieron por qué ser en exclusiva figurativo-teatrales. En concreto, entre las fuentes de los patrones detectados (e indirectamente en nuestros grabados) pudieron influir la escenografía teatral implícita en los textos terencianos, la pintura, la tradición pictórica manuscrita, el diseño arquitectónico gótico y, en particular, las crónicas y los libros de viajes ilustrados. Por razones materiales pero también técnicas y artísticas, las ilustraciones de Burgos, Sevilla y Valencia están en un estado pictórico evolutivo aún gótico-medieval, que se aviene ante todo a tradiciones y convenciones pre-renacentistas. En cambio, las xilografías alemanas de Weiditz exhiben una evolución formal más avanzada post-Burgkmair y Durero.

42.- Esta práctica remite a la técnica continuada por Grüninger y procedente de grabados alemanes anteriores, como los de la mencionada Relatio de Simone puero Tridentino (1475).

43.- Otra técnica utilizada por el grabador alemán, en connivencia con la perspectiva, es la apertura del plano en diagonal (auto II, grabado segundo), ayudando el ángulo ascendente en corrido a crear la impresión de verticalidad. 


\section{Bibliografía citada}

ABAD, Manuel. "La ilustración de portadas de La Celestina, en siete ediciones del siglo XVI». Revista de Ideas Estéticas 25 (1977): 229-35.

Alberti, León B. On painting (De pictura). Trad. Rocco Sinisgalli. New York: Cambridge UP, 2011.

Alvar, Carlos. "De la Celestina a Amadís: el itinerario de un grabado». Atti del Simposio Filologia dei Testi a Stamp (Area Ibérica). Ed. Patrizia Botta. Modena: Mucchi, 2005, pp. 97-109.

AREForD, David. "Multiplying the Sacred: The Fifteenth-Century Woodcut as Reproduction, Surrogate, Simulation». The Woodcut in Fifteenth-Century Europe. Ed. Peter Parshall. Washington DC: National Gallery of Art, 2009, 119-53.

Beneldi, Francesco. The Architecture in Giotto's Paintings. New York: Cambridge UP, 2012.

Berndt-Kelley, Erna R. "Mute Commentaries on a Text: The Illustrations of the Comedia de Calisto y Melibea». Fernando de Rojas and Celestina: Approaching the Fifth Centenary. Eds. Ivy Corfis y Joseph T. Snow. Madison: Hispanic Seminary of Medieval Studies, 1993, pp. 193-227.

Biblioteca Digital Hispánica. Biblioteca Nacional de España. <http://www. bne.es/ es/Catalogos/BibliotecaDigitalHispanica/Inicio/index.html>

Boethius. De philosophico consolatu. Strassburg: Johan Grüninger, 1501.

Bork, Robert O. The Geometry of Creation: Architectural Drawing and the Dynamics of Gothic Design. Farnham (UK): Ashgate Publishing, 2011.

BrandT, Sebastian. Das Narrenschiff: Faksimile der Erstausgabe Basel 1494 mit dem Nachwort von Franz Schultz (Strassburg 1912). Ed. Dieter Wuttke et al. Baden-Baden: Koerner, 1994.

Breindenbach, Bernardo de, y Martín Martínez de Ampiés (trad.). Viaje de la Tierra Santa. Ed. Pedro Tena Tena. Zaragoza: Institución Fernando el Católico, 2003.

Brookes, Kristin. «Discovering Melibea: Celestina's Uncontainable «doncella encerrada'». Celestinesca 24 (2000): 95-104.

Camus, Philippe. L'histoire d'Olivier de Castille et Artus d'Algarbe. Ginebra: Louis Cruse, 1492.

Capua, Juan de. Exemplario contra los engaños y peligros del mundo. Burgos: Fadrique de Basilea, 1498.

Carmona Ruiz, Fernando. "La cuestión iconográfica de la Celestina y el legado de Hans Weiditz». eHumanista 19 (2011): 79-112.

Celestina Visual. Dir. Enrique Fernández Rivera. <http://celestinavisual. org $>$. 
Cornejo, Francisco J. "Cuando la vista engaña: Los grabados de vistas de ciudades en los primeros años de la imprenta». Cartografía histórica en la Biblioteca de la Universidad de Sevilla. Coord. J. Carlos Posada Simeón, Patricio Peñalver Gómez. Sevilla: Universidad de Sevilla, 2010, pp.148-63.

Cull, John T. «A Possible Influence on the Burgos 1499 Celestina Ilustrations: The German 1486 Translation of Terence s Eunuchus». La corónica: A Journal of Medieval Hispanic Languages, Literatures \& Cultures 38. 2 (2010): 137-62

DÜreR, Albrecht. Dürer. The Complete Engravings, Etchings and Woodcuts. Ed. Karl Adolf Knappe. London: Thames and Hudson, 1965.

Esopo. Libro del Ysopo famoso fablador historiado en romançe. Burgos: Fadrique de Basilea, 1496.

-, Ysopete ystoriado. Zaragoza: Pablo Hurus, 1489.

FERnÁNDEZ RIVERA, Enrique. "Influencias de la iconografía cristiana en las ilustraciones tempranas de La Celestina». Two Spanish Masterpieces: A Celebration of the Life and Work of Maria Rosa Lida de Malkiel. Eds. I. Corfis y P. Ancos. New York: Hispanic Seminary of Medieval Studies of the Hispanic Society of America, 2013, pp. 175-95.

-, "Calisto, Leriano, Oliveros: Tres dolientes y un mismo grabado». Celestinesca 36 (2012): 119- 42.

Fletcher, Glinsman y Doris Oltrogge. «The Pigments on Hand-Colored Fifteenth-Century Relief Prints from the Collections of the National Gallery of Arta and the Germanisches Nationalmuseum». The Woodcut in Fifteenth-Century Europe. Ed. Peter Parshall. Washington DC: National Gallery of Art, 2009, 277-96.

FraXanet Sala, María Rosa. "Estudios sobre los grabados de la novela $\mathrm{La}$ Cárcel de Amor de Diego de San Pedro». Estudios de iconografía medieval española. Bellaterra: Universidad Autónoma de Barcelona, 1984, pp. 429-82.

Gilman, Stephen. The Art of La Celestina. Madison: University of Wisconsin Press, 1976.

Gómez Moreno, Ángel. «La torre de Pleberio y la ciudad de La Celestina (Un mosaico de intertextualidades artístico-literarias...y algo más)». Ed. Ignacio Arellano y J. Usunáriz. El mundo social y cultural de La Celestina. Madrid - Frankfurt am Main: Iberoamericana- Vervuert, 2003, pp. 211-33.

Grifrin, Clive. "Celestina's Illustrations». Bulletin of Hispanic Studies 78 (2001): 59-79.

Horatius Flacus, Quintus. Opera. Ed. Iacobus Locker. Strassburg: Johan Grüninger, 1498.

Huidobro, Concha et al. Durero grabador. Del Gótico al Renacimiento. Madrid: Biblioteca Nacional de España, 2012. 
KelleR, John y Richard P. KindaKe. Iconography in Medieval Spanish Literature. Lexington (KY): UP of Kentucky, 1984.

Lida de Malkiel, María Rosa. La originalidad artística de La Celestina. Buenos Aires: EUDEBA, 1962.

López DE MendozA, Iñigo (Marqués de Santillana). Bias contra Fortuna: Hecho por coplas (1902). Reprod. facs. de la ed. de: Sevilla: Stanislao Polono, 1502. [New York]: De Vinne Press, 1902.

Moner, Michel. "Espacio dramático y espacio simbólico en La Celestina de Fernando de Rojas». Studia aurea: Actas del III Congreso de la AISO (Toulouse, 1993), vol. 2. Coord. Ignacio Arellano et al. Pamplona-Toulouse: GRISO-LEMSO, 1996, pp. 279-90.

Montero, Ana Isabel. "A Penetrable Text? Illustration and Transgression in the 1499 (?) Edition of Celestina». Word \& Image 21.3 (2005): 41-55.

Needham, Paul. "Prints in the Early Printing Shops». The Woodcut in Fifteenth-Century Europe. Ed. Peter Parshall. Washington DC: National Gallery of Art, 2009, 39-91.

NORTON, Frederick J. Printing in Spain, 1501-1520; with a note on the early editions of the Celestina. Cambridge: Cambridge UP, 1966.

Panofsky, Erwin. Perspective as Symbolic Form. New York, Cambridge (MASS): Zone Books, 1997.

-, Studies in Iconology. Humanistic Themes in the Art of the Renaissance. New York: Harper Torchbooks, 1962.

POLLARD, Alfred W. Early Illustrated Books: A History of the Decoration and Illustrationof Books in the 15th and 16th Centuries. London: K. Paul, Trench \& Trubner, 1926.

RIVERA, Isidro. "Performance and Prelection in the Early Printed Editions of Celestina» Celestinesca 22.2 (1998): 3-20.

-, "Visual Structures and Verbal Representation in the Comedia de Calisto y Melibea» (Burgos, 1999?)». Celestinesca 19 (1995): 3-30.

Rodríguez-SolAz, David. "A la vanguardia del libro ilustrado: El Terencio de Lyon (1493) y La Celestina de Burgos (1499)». Bulletin of Spanish Studies 86.1 (2009): 1-17.

RojAs, Fernando de. La Celestina. Sevilla: Juan Cromberger, 1535.

-, Ain hipsche Tragedia von zwaien liebhabenden mentschen ainem Ritter Calixstus unn ainer Edlen junckfrawen Melibia genant. Trad. Christof Wirsung. Augsburg: Sigismund Grymm \& Marx Wirsung, 1520.

-, Libro de Calixto y Melibea y de la puta vieja Celestina. Sevilla: Jacobo Cromberger, 1502 (c.1518).

—, Tragicomedia de Calisto y Melibea. Valencia: Juan Joffré, 1514.

—, Comedia de Calisto y Melibea. Burgos: Fadrique de Basilea, 1499?.

Rolevinck, Wernerius. Fasciculus temporum. Auctoritates de vita et moribus philosophorum ex Laertio extractae. Hispali (Sevilla): Bartholomaeus Segura et Alphonsus de Portu, 1480. 
San Pedro, Diego de. Tractado de amores de Arnalte y Lucenda. Burgos: Fadrique de Basilea, 1491.

Scarborough, Connie. "Urban Spaces in the Tragicomedia de Calisto y Melibea». Urban Space in the Middle Ages and the Early Modern Age. Ed. Albrecht Classen. Berlin: Walter de Gruyter, 2009, pp. 537-66.

SCHedel, Hartmann et al. Liber chronicarum. Nuremberg: Anton Koberger, 1493.

Snow, Joseph T. "La iconografía de tres Celestinas tempranas (Burgos, 1499; Sevilla, 1518; Valencia, 1514): Unas observaciones». Dicenda: Cuadernos de filología hispánica 6 (1987): 255-77.

SCHMIDT, Charles. Répertoire bibliographique strasbourgeois jusque vers 1530: Jean Grüninger 1483-1531. Strassburg: Heitz \& Mündel, 1893.

Terentius, Publius. Comoediae. Cum directorio vocabulorum, glossa interlineari, et commentariis Donati, Guidonis, et Ascensii. Strassburg: Johan Grüninger, 1496.

- Terentii Comoedia sex, a Guidone Juvenale explanatae et a Jodoco Badio, cum annotationibus suis, recognitae. Lyon: Johannes Treschel, 1493.

-, Eunuchus. Hernach volget ain Maisterliche vnd wolgesetzte Comedia zelesen vnd zehören lüstig vnd kurtzwylig. Trad. Hans Nythart. Ulm: Conrad Dinckmut, 1486.

Tuberinus, Johannes M. Relatio de Simone puero Tridentino. Augsburg: Günther Zainer, 1475. http://lcweb2.loc.gov/service/rbc/rbc0001/2014/20 14rosen0060/2014rosen0060.pdf

VIDAUR y CoRTeberRía, Josefina. «El primer libro impreso en España con ilustraciones». Boletín de Bibliotecas y Bibliografía 2 (1935): 207-21.

Zumthor, Paul. La medida del mundo. Representación del espacio en la Edad Media. Madrid: Cátedra, 1994. 



\section{Álvarez-Moreno, Raúl, «Casa, torre, árbol, muro: hacia una morfología del escenario urbano en las ediciones antiguas de Celestina», Celestinesca 39 (2015), pp. 113-136.}

\section{RESUMEN}

Este artículo propone un examen morfológico de los escenarios urbanos y arquitectónicos en los grabados de las primeras ediciones españolas de Celestina (Burgos 1499, Sevilla 1502/c. 1518, Valencia 1514), en contraste con los de la traducción alemana de Augsburgo (1520). Tras considerar posibles modelos alemanes, se amplía potencialmente la influencia a modelos no procedentes de ediciones teatrales. Asimismo, se exponen patrones urbanos que en términos formales las fuentes alemanas de los grabados españoles pudieron utilizar. Entre ellos estarían la escenografía visualizada desde los propios textos dramáticos, la pintura de la época, la tradición pictórica del manuscrito, la tradición gótica del dibujo arquitectónico y, especialmente, las vistas de ciudades de los difundidos libros de viajes y crónicas. Por distintos motivos, incluidos los artísticos, el estado evolutivo de estas fuentes y, por tanto, de las ediciones españolas, correspondería a una fórmula de representación espacial y arquitectónica pre-renacentista. Ello lo confirma el análisis contrastivo de sus componentes morfológicos con los de los grabados de Hans Weideitz de la edición alemana, ya en transición hacia un mundo post-Burgkmair y Durero.

Palabras Clave: Celestina, análisis morfológico, grabados, ciudad, espacio, libros de viajes, crónicas, Durero.

\section{ABSTRACT}

This article is a morphological analysis of the urban and architectural settings in the illustrations of the first Spanish editions of Celestina (Burgos 1499, Sevi1la 1502/c. 1518, Valencia 1514). They are compared with the engravings from the German translation published in Augsburg (1520). After considering potential German antecedents the study extends the possible influences to other sources in addition to dramatic editions. The article also discusses in morphological terms the urban models that the German sources of the Spanish woodcuts could have used. These include the urban scenery visualized from dramatic texts, paintings, the pictorial manuscript tradition, the Gothic tradition of architectural drawing and, particularly, the cityscapes illustrated in popular editions, such as travel books and chronicles. Due to several reasons, including artistic ones, the evolutionary status of all these sources and, therefore, of the Spanish illustrations, fit a Pre-Renaissance spatial and architectonic design. This statement is confirmed through the analysis of their morphological components in contrast to the ones deployed by Hans Weideitz in the German translation, which already show a Post-Burgkmair and Post-Dürer perspective.

KEY WORDS: Celestina, morphological analysis, engravings, city, space, travel books, chronicles, Dürer 